\title{
Criteria for evaluating studies at scientific medical events
}

\author{
René Aloisio da Costa Vieira ${ }^{1,2,3 *}$ ๑ , Tatiana Carvalho de Souza Bonetti ${ }^{4}$, \\ Marcia Maria Chiquitelli Marques Silveira ${ }^{\top}$, Gil Facina ${ }^{4}$ (우
}

\section{ABSTRACT}

Medical journals value the quality of studies. Scientific events are spaces for discussion in the face of scientific advances, innovation and consensus. In them, space is opened for the presentation of clinical studies, translational studies, experience reports and videos, with the best-designed studies being selected and awarded. The lack of clear criteria allows for differences in assessments, making it difficult to place value on situations associated with research. In order to improve quality, it is necessary to evaluate ethics, the hierarchy of scientific evidence (methodology), the study design, the originality, the relevance, and the linearity of the material presented. The present study aims to discuss these points, presenting proposals to be used in the evaluation of clinical studies, translational studies, case reports and videos in scientific medical events.

KEYWORDS: scientific society; research design; ethics.

\section{CRITERIA FOR EVALUATING STUDIES AT SCIENTIFIC MEDICAL EVENTS}

As medical literature expands, the need to improve objective criteria for analyzing the quality of scientific studies has increased. A hierarchy of evidence based on the quality of studies was created, which offers recommendations for use in clinical practice. Likewise, the number of studies in the area of molecular biology is increasing, a fact that allows support for clinical protocols, however, the medical population has difficulty in analyzing the quality of these studies and recognizing the hierarchy of evidence.

Scientific journals can be used as quality references for studies, as readers can analyze the impact, the article's citations and the researchers' performance. The journals present their editorial board, but there are a large number of articles to be evaluated. The editors evaluate the received article and verifies if it fits the scope of the journal. They later select associate editors to perform a second evaluation. There is a tendency to select new data, which will potentially be the basis for the bibliography of other studies and, consequently, will increase impact. It is then up to authors to create or present material that has been previously rarely addressed. Case reports are no longer a priority, since they are rarely cited. As such, specific magazines have come about for the publication of this type of content.
The fact is that many studies are not published for various reasons, such as limited quality, repetition of previously discussed findings, insufficient samples, deficiencies associated with data presentation, difficulty in choosing a specific journal, failure to convince editors about the quality of the research, as well as linguistic flaws.

Scientific events are consolidated and indirectly there is a hierarchy among them. There are major world events, American or European events, national events, state events and local events. It is possible to present a study orally, in a main auditorium, in parallel auditoriums, with posters, and with e-Posters etc. The works can be published in the annals of the events or in supplemental material from the specialty's magazines, and the content can be made available in print, online or through a digital presentation only on the event website.

It should be noted that scientific events have greater flexibility than scientific journals. This is because they are spaces reserved for discussion and the dissemination of knowledge, and are associated with the need to group professionals, creating spaces for the presentation of studies and new technologies and allowing for the improvement of interpersonal relationships, and the strengthening of specialties and services. Such facts determine greater flexibility in the analysis and selection of

\footnotetext{
${ }^{1}$ Hospital de Câncer de Barretos - Barretos (SP), Brazil.

${ }^{2}$ Faculdade de Medicina de Botucatu - Botucatu (SP), Brazil.

${ }^{3}$ Hospital de Câncer de Muriaé - Muriaé (SP), Brazil.

${ }^{4}$ Universidade Federal de São Paulo - São Paulo (SP), Brazil.

*Corresponding author: reneacv@gmail.com

Conflict of interests: nothing to declare.

Received on: 05/20/2020. Accepted on: 06/01/2020.
} 
studies to be presented at the event for the scientific community. In the selective selection process, there is a relationship between quality and quantity, a fact that is influenced by the availability of space and time for presentations; in addition to the need to include services and young researchers. To enhance the quality of studies, the best studies are given awards according to selection and classification rules and scores.

The scientific committee, which is usually made up of experts with a lot of experience in the specialty, has the task of selecting the best studies. However, there is no one rule to follow. This influences the selection of papers that will be accepted at the event, as well as their classification and whether they will be offered the chance to give an oral presentation and an award.

When registering a study for a specific event, the lack of rules limits how it is valued. As such, it is necessary to discuss general rules and how they will be scored for the scientific committees. This makes the study design and presentation easier for the author. Furthermore, it brings transparency and linearity to the scientific committee of a specialty. As such, the authors present themselves through general rules that should be evaluated, contextualized and adapted for each event or specialty, in the search for greater uniformity in the studies to be sent, analyzed, compared and potentially accepted in a specific scientific event.

\section{CRITERIA RELATED TO THE METHODOLOGY OF STUDIES}

In the evaluation of the studies, it is suggested that the design, methodology (including statistical analysis), originality, authorization by the Research Ethics Committee, promotion and practical/social relevance be considered (Table 1). These items are substantiated by:

- The amount of evidence ${ }^{1}$ is associated with the methodology of the study ${ }^{2-7}$, a fact that influences the quality of the study, the degree of recommendation ${ }^{8}$ and use in clinical practice;

- Originality, bringing new aspects to light facilitates potential publication;

- Journals only accept articles if approved by a Research Ethics Committee. If this is not necessary, the Committee must state that it does not require an evaluation;

- The presence of funding suggests that the study was previously evaluated by a committee and, due to its merits, was given funding for carrying it out;

- A study's practical relevance, although not valued in publications, is important in specialty events, even in translational research, given its potential benefit to patients.

In order to facilitate the analysis in the methodology of the study, researchers can include and describe the use of scripts that are available in the literature proposed by Enhancing the Quality and Transparency of Health Research (EQUATOR) Network (https://www.equator-network.org), the main methods being used in clinical studies:

- Preferred Reporting Items for Systematic Review and MetaAnalysis (PRISMA) ${ }^{2}$ - systematic reviews;

- Consolidated Standards of Reporting Trials (CONSORT) $)^{3}-$ randomized studies;

- Strengthening the Reporting of Observational Studies in Epidemiology (STROBE) $)^{4}$ - observational studies;

- Reporting Recommendations for Tumor Marker Prognostic Studies $(\text { REMARK) })^{5}$ - prognostic markers;

- Standards for the Reporting of Diagnostic Accuracy Studies $(\mathrm{STARD})^{6}$ - diagnostic studies;

- Consensus-based Clinical Case Reporting Guideline (CARE) case studies.

In order to demonstrate prior approval by research committees, the numbers associated with this approval should be presented. The main ones are:

- The Research Ethics Committee approval number;

- The registration of randomized clinical studies in national (ReBEC) or international (ClinicalTrials) platforms;

- The agency that gave grants to the study and its number.

Many papers submitted to conferences constitute reports or a series of cases. Such studies should be evaluated in detail, given their frequency in national and regional conferences. The fact is that there is no classification for them, and many papers may not be accepted because the presentation was inadequate, because the rarity of the event was not valued, or because a particular and rare aspect of the case addressed was unable to be presented. For the best selection of these studies, several criteria are considered, which are presented in Table 2, in which the reports are evaluated for having approval by the local Research Ethics Committee; they are rare and complex based on the evaluation of the literature, innovation of the aspect addressed, description and detailed documentation of the case.

In addition to clinical studies, we should emphasize the importance of research in basic and translational science. While basic science employs experimental data that will provide a basis for clinical research, translational studies allow the research results to be moved from theory to clinical practice in the community 9 For this, the methodology should be described in the greatest possible detail and evaluated respecting the caveats inherent to experimental studies (Table 3).

Given the current context, we suggest that scientific events analyze clinical studies, molecular biology studies and case reports separately, with the purpose of classifying them objectively and giving them awards in different categories. As such, there is the possibility of valuing good case reports so that they receive honorable mentions. 


\section{FORMATTING OF THE STUDIES TO BE PRESENTED}

The lack of specific formatting hinders an author's design and impairs the comparative evaluation of the reviewers. In order to standardize the studies that are prepared for scientific events, the criteria presented in Tables 1 to 3 are proposed:

- General presentation:
- Study title;

- Authors' names;

- Institution where the study was carried out;

- Number of words in the abstract, up to 300;

- Text structured according to the type of study

- clinical and molecular biology studies: introduction, materials and methods, results, conclusions;

Table 1. Proposal of criteria and scores to be used in conferences and scientific events.

\begin{tabular}{|c|c|}
\hline Points & Criteria \\
\hline & Study methods \\
\hline 2.8 & Systematic review of randomized studies with or without a meta-analysis \\
\hline 2.4 & Randomized experimental studies \\
\hline 2.0 & Cohort Studies \\
\hline 1.6 & Case control studies \\
\hline 1.2 & Case series \\
\hline 0.8 & Case report \\
\hline \multirow[t]{2}{*}{0.4} & Expert opinions \\
\hline & Research Ethics \\
\hline 1.0 & Approval from the ethics committee \\
\hline 1.0 & No need for a Research Ethics Committee under Resolution No. 466 \\
\hline \multirow[t]{2}{*}{0.0} & No description or evaluation by the ethics committee \\
\hline & Study Design \\
\hline 2.5 & $\begin{array}{l}\text { Adequate description of the study with clear, reproducible methodology, consistent results and adequate conclusion that } \\
\text { is compatible with the data presented. Approved through ClinicalTrials/ReBEC or something similar. }\end{array}$ \\
\hline 2.0 & $\begin{array}{l}\text { Adequate description of the study with clear, reproducible methodology, consistent results and adequate conclusion that } \\
\text { is compatible with the data presented. Not approved through ClinicalTrials/ReBEC or something similar. }\end{array}$ \\
\hline 1.5 & $\begin{array}{l}\text { Adequate description of the study, however the methodology is weak (not reproducible), consistent results and adequate } \\
\text { conclusion that is compatible with the data presented. }\end{array}$ \\
\hline 1.0 & $\begin{array}{l}\text { Adequate description of the study, however the methodology is weak (not reproducible), and the results and/or } \\
\text { conclusions were not adequate for the data presented. }\end{array}$ \\
\hline 0.5 & Severe failures in the introduction, methodology, results and conclusions. \\
\hline \multirow[t]{2}{*}{0.0} & Does not apply. Methodology and results not described. \\
\hline & Originality \\
\hline 1.7 & Unprecedented - new interpretation of the concept \\
\hline 1.2 & Ratifies a known concept that is optional \\
\hline 0.7 & Ratifies a classic concept that is used everyday \\
\hline \multirow[t]{2}{*}{0.4} & Does not introduce a new concept \\
\hline & Promotion \\
\hline 1.0 & Promotion from a public agency \\
\hline 0.5 & Promotion from a private agency \\
\hline \multirow[t]{2}{*}{0.0} & Self-promotion or no promotion \\
\hline & Practical/social relevance \\
\hline 1.0 & Applicable at any center \\
\hline 0.5 & Applicable only in a private or public center that is an exception (ex. has many resources) \\
\hline 0.0 & No clinical applicability or does not fit \\
\hline
\end{tabular}

ReBEC: Registro Brasileiro de Ensaios Clínicos (Brazilian Registry of Clinical Trials). 
- case report:introduction, case description, literature review and conclusion (optional if there are revisions);

- Study registration numbers: Research Ethics Committee; authorization of the patient - case reports that are not approved by the Research Ethics Committee, or that use photos, must have authorization signed by the patient or legal guardian, and this must be written in the text (example: "obtained authorization of the patient to use information”) -; clinical record (ReBEC or ClinicalTrials); promotion (agency, number); auxiliary methodology (PRISMA, CONSORT, STROBE, REMARK, STARD, CARE). At the discretion of the commission, giving proof of this data may or may not be requested.

\section{SCIENTIFIC VIDEOS}

The use of scientific videos is frequent in surgical conferences in order to demonstrate technical and tactical aspects of surgery that are relevant and innovative, or to present tactics conducted by surgeons with extensive experience in specific procedures. The selection of videos is a little more complex due to the content of the abstract and the procedure to be presented in the proceedings of the event. Furthermore, the video itself needs to be evaluated since the best videos will be presented and discussed in a specific place. Due to the different nature of videos, how they are awarded must also be different.

It is advisable that the abstract be structured, observing: an introduction to the theme, principal suggestions; a presentation of the particularities of the case or theme that justify the importance of the video; the technical care to be taken; and the main complications associated with the procedure.

In the video presentation rules, the time ( 5 to $7 \mathrm{~min}$ ), the digital format (mp4, wmv, mpg, mpeg, avi, flv) and the minimum resolution (720 dpi) must be specified, in addition to the methodology used for sending and viewing it (Youtube, Dropbox).

Organization and linearity are the lifeblood of the video, demonstrated by an introduction to the topic, the presentation of particularities of the case that justify the importance of the video, the technique, the surgical tactic and the final result. Table 4 presents proposed criteria and specific scores for comparative video analysis.

\section{RESEARCH ETHICS}

The Brazilian Resolution no. 466/2012 of the National Commission for Ethics in Research (Comissão Nacional de Ética em Pesquisa CONEP) regulates studies that are carried out on humans and will be published ${ }^{10}$. Circular Letter 166/2018 regulates the publication of case reports ${ }^{11}$.

Table 2. Proposal of criteria to be used in conferences and scientific events for case reports and case series.

\begin{tabular}{|c|c|}
\hline Points & Criteria \\
\hline & Research Ethics \\
\hline 1.0 & Approval by the ethics committee \\
\hline 0.5 & Authorization from the patient \\
\hline 0.0 & No description or evaluation from the Ethics Committee \\
\hline & Complexity \\
\hline 2.0 & Case with a systematic review \\
\hline 1.0 & Case with no systematic review \\
\hline 0.5 & Description exclusive to the case \\
\hline & Rarity \\
\hline 4.0 & Extremely rare (< 50 cases described) \\
\hline 3.0 & Rare (<200 cases described) \\
\hline 2.0 & Uncommon (< 500 cases described) \\
\hline 0.5 & Common \\
\hline & Aspect addressed \\
\hline 1.0 & Innovative \\
\hline 0.5 & Common \\
\hline & Description \\
\hline 2.0 & Good and concise \\
\hline 1.0 & Fair \\
\hline 0.5 & Non-linear, confusing \\
\hline
\end{tabular}


Scientific events are spaces to discuss and disseminate knowledge among health professionals. They focus on a specialty, but they allow for a multi-professional space. The act of including ethical scores in studies aims to value and emphasize the care of this nature in human studies, in addition to identifying and selecting the best works, which will be presented in a free form or will be directed toward future publications. Similarly, including these scores in the videos aims to improve patient care and identify those with potential for publication.

Scientific events may have greater flexibility in relation to the presentation of findings. Care must be taken as to not unnecessarily submit studies to the CONEP system, if they are not meant for scientific publication. In the presence of case reports and videos, regardless if they are included on Plataforma Brasil ${ }^{12}$, it is necessary to maintain patient confidentiality, even when using images. Patient consent is also essential and must be included in the medical record. In videos that demonstrate scientific experience or for case reports that won't be published, it does not make sense to have them be evaluated by the CONEP system.

\section{FINAL CONSIDERATIONS}

If the event chooses to use a specific language, such as English, the author is responsible for the translation, and a study in a language other than the requested criterion will not be accepted.

Table 3. Proposal of criteria to be used in molecular biology studies.

\begin{tabular}{|c|c|}
\hline Points & Criteria \\
\hline & Study methods \\
\hline 2.8 & Omics studies (genomics, transcriptomics, proteomics) \\
\hline 2.4 & Functional studies (in vitro/in vivo) \\
\hline 2.0 & The identification of biomarkers (with validation methodology) \\
\hline 1.6 & Case control studies \\
\hline 1.2 & Descriptive studies without validation or without a control group \\
\hline \multirow[t]{2}{*}{0.8} & Studies that do not fit into the items previously mentioned \\
\hline & Study Design \\
\hline 2.5 & $\begin{array}{l}\text { Description of the study is clear and has an adequate sample size, and methodology that is compatible with the objectives, } \\
\text { results and conclusions }\end{array}$ \\
\hline 2.0 & $\begin{array}{l}\text { Description of the study is clear but there is no sample size that supports the proposed methodology and results } \\
\text { (non-reproducible methodology) }\end{array}$ \\
\hline 1.5 & Serious flaws in the description of the study, methodology and results \\
\hline \multirow[t]{2}{*}{1.0} & Does not apply. No methodology in the field of molecular biology \\
\hline & Research Ethics \\
\hline 1.0 & Approval by the Ethics Committee (or science for studies with commercial cell lines) \\
\hline 1.0 & No need for a Research Ethics Committee under Resolution No. 466, and a description in the study \\
\hline \multirow[t]{2}{*}{0.0} & No description or evaluation from the Ethics Committee \\
\hline & Originality / Innovation \\
\hline 1.7 & Unprecedented - new interpretation of the concept \\
\hline 1.2 & Ratifies a known concept that is optional \\
\hline 0.7 & Ratifies a classic concept that is used everyday \\
\hline \multirow[t]{2}{*}{0.4} & Does not introduce a new concept \\
\hline & Promotion \\
\hline 1.0 & Promotion from a public agency \\
\hline 0.5 & Promotion from a private agency \\
\hline \multirow[t]{2}{*}{0.0} & Self-promotion or no promotion \\
\hline & Clinical correlation \\
\hline 1.0 & In the study design and clinical practice \\
\hline 0.5 & In the study design \\
\hline 0.0 & Not applicable in clinical practice \\
\hline
\end{tabular}


Table 4. Proposal of criteria and scores to be used in conferences and scientific events for scientific videos.

\begin{tabular}{|c|c|}
\hline \multirow{2}{*}{ Points } & Criteria \\
\hline & ABSTRACT \\
\hline & Ethics \\
\hline 1.0 & $\begin{array}{l}\text { Authorization from the patient. Declaration of conflict of interest. Approval from the Ethics Committee } \\
\text { (in the publication proposal). }\end{array}$ \\
\hline 0.5 & Authorization by the patient and/or declaration of conflict of interest \\
\hline \multirow[t]{2}{*}{0.0} & No description or evaluation by the Ethics Committee \\
\hline & Structured Abstract \\
\hline 1.5 & Good, linear and concise \\
\hline 1.0 & Fair \\
\hline 0.5 & Non-linear, confusing \\
\hline \multicolumn{2}{|r|}{ VIDEO } \\
\hline & Originality \\
\hline 1.5 & Relevant and Innovative \\
\hline 1.0 & Relevant or Innovative \\
\hline \multirow[t]{2}{*}{0.5} & Common \\
\hline & Practical interest - clinical applicability \\
\hline 1.5 & Little-known procedure or adds new approach \\
\hline 1.0 & Well-known procedure and adds new approach \\
\hline \multirow[t]{2}{*}{0.5} & Well-known procedure and does not add new approach \\
\hline & Didactic practices \\
\hline 2.0 & Linearity and clarity \\
\hline 1.0 & Small technical limitations \\
\hline \multirow[t]{2}{*}{0.5} & Major technical limitations \\
\hline & Quality: image, sound and content \\
\hline 1.5 & Good presentation of the field and surgical tactics. Cleaning of the surgical field. \\
\hline 1.0 & Small technical limitations \\
\hline \multirow[t]{2}{*}{0.5} & Major technical limitations \\
\hline & Interest: general format \\
\hline 1.0 & Compliance with the event rules (format, size) \\
\hline 0.5 & Technical limitations \\
\hline
\end{tabular}

Some committees have sections in which the article should be designed according to its main characteristics, at the time of data inclusion. This will facilitate the organization of the annals and favor research by the event participants.

When inserting the data, the main author must indicate that it is authorized for publication in the annals of the event, and take responsibility for the property and veracity of the data presented.

The present work does not wish to present a rule, but a script to be used or improved for future events, which will assist researchers and scientific committees. Likewise, it intends to value aspects to be presented by the researcher, in order to demonstrate the seriousness and quality of his or her research.
Lastly, it aims to provide transparency and value the discussions present at the scientific event.

\section{AUTHORS' CONTRIBUTION}

RACV,TCSB, MMCMS and GF participated in all of the steps related to this publication. All authors performed: substantial contributions to the conception or design of the work; the acquisition, analysis, or interpretation of data for the work; the drafting of the work or critical revisions for important intellectual content; final approval of the version to be published; agreement to be accountable for all aspects of the work; and ensuring that questions related to the accuracy or integrity of any part of the work are appropriately investigated and resolved. 


\section{REFERENCES}

1. Cook DJ, Guyatt GH, Laupacis A, Sackett DL, Goldberg RJ. Clinical recommendations using levels of evidence for antithrombotic agents. Chest. 1995;108(4 Supl.):227S-30S. http://doi.org/10.1378/chest.108.4_supplement.227s

2. Stewart LA, Clarke M, Rovers M, Riley RD, Simmonds M, Stewart G, et al. Preferred Reporting Items for Systematic Review and Meta-Analyses of individual participant data: the PRISMA-IPD Statement. JAMA. 2015;313(16):1657-65. http:// doi.org/10.1001/jama.2015.3656

3. Schulz KF, Altman DG, Moher D, Group C. CONSORT 2010 statement: updated guidelines for reporting parallel group randomised trials. PLoS Med. 2010;7(3):e1000251. http://doi. org/10.1371/journal.pmed.1000251

4. Vandenbroucke JP, von Elm E, Altman DG, Gotzsche PC, Mulrow CD, Pocock SJ, et al. Strengthening the Reporting of Observational StudiesinEpidemiology(STROBE): explanation and elaboration.Int J Surg. 2014;12(12):1500-24. http://doi.org/10.1016/j.ijsu.2014.07.014

5. McShane LM, Altman DG, Sauerbrei W, Taube SE, Gion M, Clark GM, Statistics Subcommittee of NCIEWGoCD. Reporting recommendations for tumor MARKer prognostic studies (REMARK). Breast Cancer Res Treat. 2006;100(2):22935. http://doi.org/10.1007/s10549-006-9242-8

6. Cohen JF, Korevaar DA, Altman DG, Bruns DE, Gatsonis CA, Hooft L, et al. STARD 2015 guidelines for reporting diagnostic accuracy studies: explanation and elaboration. BMJ Open. 2016;6:e012799. http://doi.org/10.1136/bmjopen-2016-012799
7. Gagnier JJ, Kienle G, Altman DG, Moher D, Sox H, Riley D, et al. The CARE guidelines: consensus-based clinical case reporting guideline development. J Med Case Rep. 2013;7:223. http://doi. org/10.1186/1752-1947-7-223

8. Oxford Centre for Evidence-based Medicine. Nível de Evidência científica por tipo de estudo [Internet]. Oxford Centre for Evidence-based Medicine; 2020 [accessed on May 1, 2020]. Available at: http://conitec.gov.br/images/ Artigos_Publicacoes/Oxford-Centre-for-Evidence-BasedMedicine.pdf

9. Rubio DM, Schoenbaum EE, Lee LS, Schteingart DE, Marantz PR, Anderson KE, et al. Defining translational research: implications for training. Acad Med. 2010;85(3):470-5. http:// doi.org/10.1097/ACM.0b013e3181ccd618

10. Padilha ARS. Resolução n 466, de 12 de dezembro de 2012 [Internet]. Brasília: Conselho Nacional de Saúde; 2012 [accessed on May 1, 2020]. Available at: http://www.conselho. saude.gov.br/resolucoes/2012/Reso466.pdf

11. Venancio JAA. Carta Circular no 166/2018-CONEP/SECNS/ MS [Internet]. Brasília: Conselho Nacional de Saúde; 2018 [accessed on May 1, 2020]. Available at: http://conselho.saude. gov.br/images/comissoes/conep/documentos/CARTAS/ CartaCircular166.pdf

12. Ministério da Saúde. Plataforma Brasil [Internet]. [accessed on May 1, 2020]. Available at: http://plataformabrasil.saude.gov. br/login.jsf 